\title{
Aspect sensitivity in the VHF radar backscatters studied using simultaneous observations of Gadanki MST radar and GPS sonde
}

\author{
A. K. Ghosh, S. S. Das, A. K. Patra, D. N. Rao, and A. R. Jain \\ National MST Radar Facility, P. B. 123, Tirupati 517502, A. P., India
}

Received: 1 December 2003 - Revised: 12 July 2004 - Accepted: 25 October 2004 - Published: 29 November 2004

Part of Special Issue "10th International Workshop on Technical and Scientific Aspects of MST Radar (MST10)"

\begin{abstract}
Simultaneous observations made on four days using the MST radar and GPS-sonde at Gadanki $\left(13.5^{\circ} \mathrm{N}\right.$, $79.2^{\circ} \mathrm{E}$ ), a tropical station in India, are presented to address the aspect sensitivity of radar backscatters observed at different heights. The observations show that wherever stability parameter $\mathrm{N}^{2}$ is high, vertical shear of horizontal wind is low and Richardson number $\left(\mathrm{R}_{i}\right)$ is high, the aspect sensitivity is high indicating that the aspect sensitive radar backscatters are due to thermal structures in the atmosphere. Such a case can be seen very clearly in the upper troposphere and lower stratosphere. At some heights, where $\mathrm{N}^{2}$ is high, $\mathrm{R}_{i}$ is high, but shears are relatively weak, the aspect sensitivity is found to almost disappear, indicating that some amount of shear provides favorable conditions for causing aspect sensitivity. Aspect sensitivity does not occur at all where $\mathrm{N}^{2}$ is low or negative and $\mathrm{R}_{i}$ is low in spite of wind shear being either high or low, indicating that the regions are well mixed and hence turbulent. The study also shows a power difference in the symmetric beams. A case study on this aspect suggests that this asymmetry is due to the tilting of layers by the action of atmospheric waves. There is indication that these waves are generated through Kelvin-Helmholtz-instability (KHI).
\end{abstract}

Key words. Meteorology and atmospheric dynamics (middle atmosphere dynamics; turbulence) - Electromagnetics (scattering and diffraction)

\section{Introduction}

Radar echoes from lower and middle atmosphere at VHF are known to be aspect sensitive, which is characterized by a decrease in echo power as the radar beam is pointed away from the zenith (Gage and Green, 1978; Röttger and Liu, 1978; Fukao et al., 1980). Study of aspect sensitivity at VHF in the lower atmosphere is of significant interest to the radar community, as it is important to understand the characteristics of the radar backscatters for better interpretation of the spectral

Correspondence to: A. K. Ghosh

(asish_gh@rediffmail.com) parameters, which represent various atmospheric parameters. The scattering mechanisms responsible for giving rise to VHF radar echoes are isotropic/anisotropic turbulent fluctuations in refractive index and Fresnel reflection/scattering due to sharp gradients in the refractive index. In a direction close to vertical incidence, radar echoes are enhanced because of a single or multiple strafied horizontal layers with sharp gradient in radio refractive index (Fresnel reflection/scattering) (Röttger and Liu, 1978) and/or anisotropic turbulence. The backscattered signal at VHF for beam zenith angle greater than $10^{\circ}$ arises mainly due to the refractive index irregularities associated with isotropic scattering at the Bragg scale, which is half the radar wavelength (Narayana Rao et al., 1997). The generation mechanisms of these irregularities, at various height levels in the troposphere and lower stratosphere (up to $25 \mathrm{~km}$ ) are yet to be fully understood. There are two main causative mechanisms for aspect sensitive radar backscatter: 1) specular reflectors and 2) anisotropic refractive index irregularities (Gage and Green, 1978; Doviak and Zrinc, 1984; Hocking and Hamza, 1997). The contribution of each of these mechanisms at various height levels, however, could not be well determined due to lack of simultaneous high resolution radar and in-situ measurements of background atmospheric parameters.

There have been many efforts to understand the aspect sensitive nature of the radar echoes (Gage et al., 1981a,b; Crane, 1980; Doviak and Zrinc, 1984; Tsuda et al., 1986; Woodman and Chu, 1989; Hocking et al., 1990; Yoe et al., 1994; Jain et al., 1997). Most of the aspect sensitivity related studies so far have been carried out at mid-, and high-latitudes. These studies have shown that aspect sensitivity is more at upper troposphere and lower stratosphere. There are only a few studies related to aspect sensitivity from tropical latitudes (Röttger et al., 1981; Worthington et al., 1999; Damle et al., 1994; Jain et al., 1997). Recently, there have been considerable efforts to understand radar backscatter and the aspect sensitivity of the radar echoes in terms of background atmospheric parameters (Tsuda et al., 1997a,b; Jain et al., 1997; Hooper and Thomas, 1998; Palmer et al., 1998; Worthington et al., 1999; Hobbs and Reid, 2000; Jain et al., 2001, 2003). 
These observations have shown that there could be significant contribution from the enhancement in $\mathrm{N}^{2}$ (Hooper and Thomas, 1998). Luce et al. (2001) have discussed contribution of temperature sheets to the aspect sensitive radar echoes. The above authors pointed out that the zenith and azimuth angle dependence of the echo power may arise either due to diffuse reflection from stable layers, or distorted/corrugated sheets or contribution from anisotropic turbulence occurring in the stratified atmosphere. Jain et al. (2001, 2003) have shown that, at some heights, echoes are from sharp gradients in radio refractivity structures associated with anisotropic turbulence. A number of attempts have also been made to understand the aspect sensitivity and its azimuthal anisotropy in terms of the background atmospheric parameters, such as winds and vertical shears of horizontal winds, using simultaneous radar measurements both in Doppler Beam Swinging (DBS) and Space Domain Interferometry (SDI) modes (Palmer et al., 1998; Hobbs and Reid, 2000; Kawano et al., 2001). Kawano et al. (2001) observed backscatter layers to be tilted in zonal plane by $0.7^{\circ}$ and this tilt was used to correct the observed velocity. Worthington and Thomas (1997) reported that there is a power difference between two symmetric beams, which they attributed to the tilting of the refractive index gradient layers. The observed tilt of the layers was related to the passage of gravity waves. It is thus evident that the background atmospheric parameters affect the aspect sensitivity of the radar received echo power.

In this paper, an attempt is made to understand the origin of aspect sensitivite characteristics of the radar backscatters at VHF using simultaneous observations made by the MST radar and GPS sonde (Vaisala type) from Gadanki $\left(13.5^{\circ} \mathrm{N}\right.$, $79.2^{\circ} \mathrm{E}$ ), a tropical station in India. An attempt is also made to understand the possible mechanisms for tilting the layers and their contributions to aspect sensitivity.

\section{Theory}

The basic concepts of aspect sensitivity have been discussed in several papers (Hocking et al., 1986; Hocking, 1989; Hocking et al., 1990; Damle et al., 1994; Jain et al., 1997). To simplify the concept, the polar diagram of backscatter is assumed to be proportional to $\exp \left(\frac{-\sin ^{2} \theta}{\sin ^{2} \theta_{s}}\right)$ (Hocking et al., 1986), where $\theta$ is the beam pointing angle and $\theta_{s}$ is the $\mathrm{e}^{-1}$ times the half width of the polar diagram. It is implied that small values of $\theta_{s}$ refer to large anisotropy and values of $\theta \gg \theta_{s}$ and close to $90^{\circ}$ refer to isotropic scattering, the latter being due to refractive index fluctuations associated with isotropic turbulence. The parameters $\theta_{s}$ can be determined using the received backscatter powers observed at two zenith angles, say $\theta_{1}$ and $\theta_{2}$ (Hocking, 1989; Hocking et al., 1990; Hooper and Thomas, 1995).

$$
\theta_{s}=\sin ^{-1} \sqrt{\frac{\sin ^{2} \theta_{2}-\sin ^{2} \theta_{1}}{\ell n\left[\frac{P\left(\theta_{1}\right)}{P\left(\theta_{2}\right)}\right]}-\sin ^{2} \theta_{0}} .
$$

Table 1. Experiment Specification File (ESF) used for the MST radar observations.

\begin{tabular}{ll}
\hline Parameter & Specification \\
\hline Inter Pulse Period $(\mu \mathrm{s})$ & 1000 \\
Pulse width $(\mu \mathrm{s})$ & 16 \\
Coded/Uncoded & Coded with $1 \mu$ baud \\
Range resolution $(\mathrm{m})$ & 150 \\
No. of beams & 36 (see Fig. 1) \\
No. of FFT points & 128 \\
No. of Coherent Integrations & 64 \\
Incoherent integrations & 1 \\
Observational Window: $(\mathrm{km})$ & $3.6-32$ \\
\hline
\end{tabular}

The parameter $\theta_{s}$ is a measure of aspect sensitivity and $\theta_{0}$ is a measure of antenna beam width as described by the polar diagram of the vertically directed beam. As a special case, when one of the beams is at zenith, Eq. (1) can be simplified as

$\theta_{s}=\sin ^{-1} \sqrt{\frac{\sin ^{2} \theta_{t}}{\ell n\left[\frac{P(0)}{P\left(\theta_{t}\right)}\right]}-\sin ^{2} \theta_{0}}$,

where $\theta_{1}=0$ and $\theta_{2}=\theta_{t}$, where $\theta_{t}$ is the tilt angle of the beam.

Equations (1) and (2) can be used to compute $\theta_{s}$ at the height where $\mathrm{P}\left(\theta_{1}\right)>\mathrm{P}\left(\theta_{2}\right)$ for various beam combinations. The values of $\theta_{s} \leq 5^{\circ}$ indicate a reflection mechanism other than that caused by turbulence (Hocking and Hamza, 1997).

\section{Observations}

Gadanki MST radar is a highly sensitive pulsed Doppler radar operating at a frequency of $53 \mathrm{MHz}$ with a peak power aperture product of $3 \times 10^{10} \mathrm{Wm}^{2}$. The technical features of this radar viz. system description, signal processing and data processing details have been discussed by Rao et al. (1995). The main beam can be steered between $\pm 20^{\circ}$ off zenith angle in two orthogonal planes, i.e. east-west (E-W) and northsouth $(\mathrm{N}-\mathrm{S})$. The antenna beam width is $3^{\circ}$ and corresponding to this value

$\theta_{0}\left[=\frac{\theta_{3 d B}}{2 \sqrt{\ln 2}}\right]$ is $1.8^{\circ}$.

Observations were carried out using the Gadanki MST radar on 21 September, 25 September, 8 October and 11 October 2002 to study the aspect sensitivity. On each day, observation period was 13:00-20:00 IST (i.e. 07:30-14:30 UT). For these experiments, a pulse length of $16 \mu$ s coded with the baud length of $1 \mu \mathrm{s}$ (range resolution of $150 \mathrm{~m}$ ) was used. The Experimental Specification File (ESF) used for these observations is given in Table 1. The radar beam is tilted in steps of $3^{\circ}$ within $15^{\circ}$ on either side of zenith in E-W and $\mathrm{N}-\mathrm{S}$ planes and at zenith (i.e. $3^{\circ} \mathrm{N}, 3^{\circ} \mathrm{S}$, Zenith, $3^{\circ} \mathrm{E}$, 
Table 2. Location of the balloon as a function of height for four different days (21 September, 25 September, 8 October and 11 October 2002 ).

\begin{tabular}{|c|c|c|c|c|c|c|c|c|}
\hline \multirow{2}{*}{$\begin{array}{l}\text { Time } \\
(\min )\end{array}$} & \multicolumn{2}{|c|}{21 September 2002} & \multicolumn{2}{|c|}{25 September 2002} & \multicolumn{2}{|c|}{8 October 2002} & \multicolumn{2}{|c|}{11 October 2002} \\
\hline & $\mathrm{D}^{*}$ & $\mathrm{Ht}^{* *}$ & $\mathrm{D}^{*}$ & $\mathrm{Ht}^{* *}$ & $\mathrm{D}^{*}$ & $\mathrm{Ht}^{* *}$ & $\mathrm{D}^{*}$ & $\mathrm{Ht}^{*}$ \\
\hline 15 & 0.20 & 3.15 & 0.10 & 3.49 & 0.36 & 2.69 & 0.09 & 2.69 \\
\hline 20 & 0.22 & 4.53 & 0.20 & 5.06 & 0.41 & 4.11 & 0.09 & 4.10 \\
\hline 25 & 0.42 & 5.75 & 0.22 & 6.37 & 0.67 & 5.58 & 0.11 & 5.47 \\
\hline 30 & 0.36 & 7.18 & 0.40 & 7.70 & 0.69 & 7.01 & 0.22 & 6.83 \\
\hline 35 & 0.40 & 8.41 & 0.58 & 9.80 & 0.73 & 8.48 & 0.31 & 8.10 \\
\hline 40 & 0.42 & 9.75 & 0.89 & 10.23 & 0.83 & 10.13 & 0.22 & 9.48 \\
\hline 45 & 0.91 & 10.96 & - & - & 0.95 & 11.69 & 0.28 & 10.94 \\
\hline 50 & 1.10 & 12.48 & 1.53 & 13.25 & 1.11 & 13.18 & 0.22 & 12.34 \\
\hline 55 & 2.48 & 13.97 & 4.90 & 14.72 & 1.35 & 14.62 & 0.20 & 13.91 \\
\hline 60 & 4.8 & 15.38 & 5.03 & 16.17 & 1.74 & 15.91 & 0.27 & 15.41 \\
\hline 65 & 5.13 & 16.84 & 5.53 & 17.65 & 2.18 & 17.72 & 0.43 & 16.99 \\
\hline
\end{tabular}

-: Data is not available

D: Horizontal distance from radar site in $\mathrm{km}$

$\mathrm{H}$ : Vertical height in $\mathrm{km}$

$3^{\circ} \mathrm{W}$, Zenith, $6^{\circ} \mathrm{N}, 6^{\circ} \mathrm{S}$, Zenith, $6^{\circ} \mathrm{E}, 6^{\circ} \mathrm{W}$, Zenith, $9^{\circ} \mathrm{N}$, $9^{\circ} \mathrm{S}$, Zenith, $9^{\circ} \mathrm{E}, 9^{\circ} \mathrm{W}$, Zenith, $12^{\circ} \mathrm{N}, 12^{\circ} \mathrm{S}$, Zenith, $12^{\circ} \mathrm{E}$, $12^{\circ} \mathrm{W}$, Zenith, $15^{\circ} \mathrm{N}, 15^{\circ} \mathrm{S}$, Zenith, $15^{\circ} \mathrm{E}, 15^{\circ} \mathrm{W}$, Zenith), which is shown in Fig. 1. After completing one set of such observations, another set of observations using $10^{\circ}$ off zenith beam (our standard mode of operations) was also collected for background wind estimation.

Simultaneous GPS-sonde observations were also made from Gadanki for these four days at 16:30 IST. GPS sonde reached an altitude of $24-26 \mathrm{~km}$ in just one and a half hours from the time of release. GPS sonde measurements of temperature, pressure, humidity, wind speed and wind direction were obtained at every one-second interval, corresponding to a vertical resolution of approximately $5 \mathrm{~m}$. In order to have a meaningful comparison and synthesis of the balloon and radar data, it is important to know the location of the balloon as a function of time. The location of the balloon as a function of height is given in Table 2 for three different days. It is found that the locations of the balloon are well within the region of radar measurements, except at the height of about $16 \mathrm{~km}$, where the balloon is about $1 \mathrm{~km}$ away from the region of interest. To make radar and GPS sonde measurements comparable, a fixed-point interval of 150-m linear interpolation was performed. The radar measurements of echo power, vertical shear of horizontal wind as a function of height are presented. These represent average values over one and a half hour corresponding to the GPS-sonde observations. These measurements are used to determine height profiles of atmospheric static stability parameter $\left(\mathrm{N}^{2}\right)$, where $\mathrm{N}$ is the Brunt-Väisälä frequency. The parameters $\mathrm{N}^{2}$ are defined as $N^{2}=\frac{g}{\theta}\left(\frac{d \theta}{d z}\right)$, where $\mathrm{g}$ is acceleration due to gravity, $\theta$ is potential temperature. The simultaneous MST radar and GPS sonde observations are used to estimate the Richardson

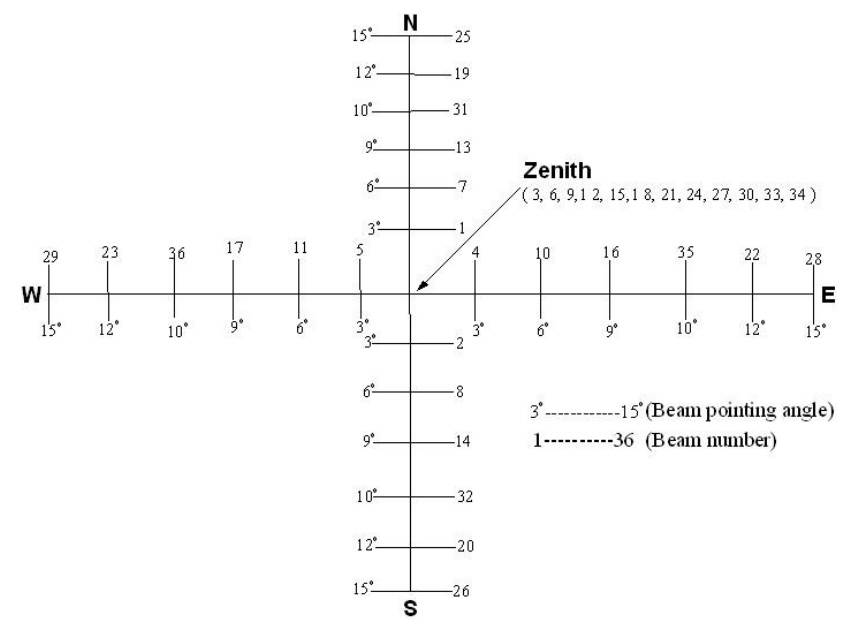

Fig. 1. Beam switching pattern in E-W and N-S planes of the antenna array, used for the present study of aspect sensitivity. The beam scan number and zenith angle of the beam are also given.

number $\left(\mathrm{R}_{i}=\mathrm{N}^{2} / \mathrm{S}^{2}\right.$, where $\mathrm{S}$ is the vertical shear of horizontal winds).

\section{Results and discussion}

Figures $2 \mathrm{a}-\mathrm{d}$ show the height profiles of echo power for different beam zenith angles $\left(0^{\circ}, 3^{\circ}, 6^{\circ}, 9^{\circ}, 12^{\circ}\right.$ and $\left.15^{\circ}\right)$ in E$\mathrm{W}$ and $\mathrm{N}-\mathrm{S}$ planes, stability parameter $\mathrm{N}^{2}$, square of the vertical shear of horizontal winds $\left(\mathrm{S}^{2}\right)$ and Richardson number $\left(\mathrm{R}_{i}\right)$, observed on 21 September, 25 September, 8 October and 11 October 2002, respectively. It may be mentioned that the sensitivity of the radar was the same for all four days. The 

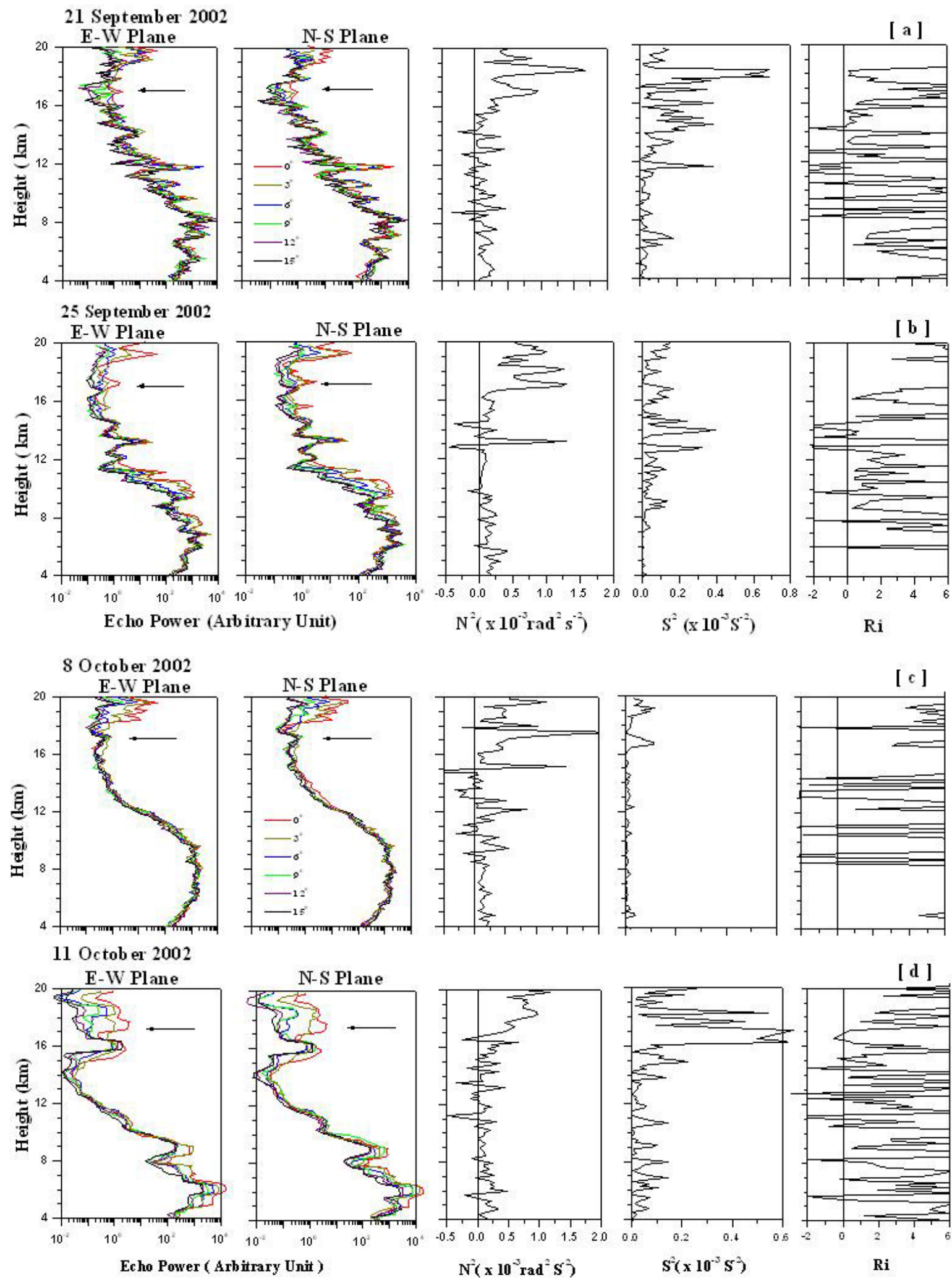

[ d ]

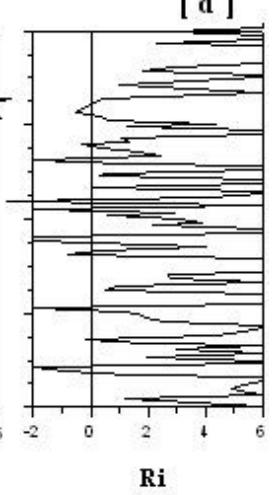

Fig. 2. Figures 2(a)-(d): Height profiles of radar echo power for different beam positions in E-W and N-S planes for (a) 21 September, (b) 25 September, (c) 8 October and (d) 11 October 2002. Height profiles of $\mathrm{N}^{2}$, square of vertical shear of horizontal winds $\left(\mathrm{S}^{2}\right)$ and Richardson number $\left(\mathrm{R}_{i}\right)$ are also plotted side by side. The horizontal arrow in each panel of power profiles represents the height of the tropical tropopause obtained GPS sonde observation. 
wind shears shown here are computed using the radar measurements. The height profiles of $\mathrm{N}^{2}, \mathrm{~S}^{2}$ and $\mathrm{R}_{i}$ are presented side by side in order to have a close comparison of these parameters with the power profiles, which are discussed later.

The echo power profiles presented here are one and a half hour average values corresponding to 16:30-18:00 IST. The horizontal arrow in the panel of power profiles shows the height of tropopause obtained from GPS sonde for each day of observation. The power profiles of 25 September and 11 October appear to have two distinct regions where the observed radar echoes are aspect sensitive. The two regions are: height range of 7-11.5 km on 25 September and $5-9 \mathrm{~km}$ on 11 October and above $14 \mathrm{~km}$ on both days. The aspect sensitive feature can be noticed in both $\mathrm{E}-\mathrm{W}$ and $\mathrm{N}-\mathrm{S}$ planes. The received echo powers at higher beam angles $\left(>9^{\circ}\right)$ are almost equal. In contrast to the observations of 25 September and 11 October, the observed echo powers do not appear to have aspect sensitivity below $15 \mathrm{~km}$ on 21 September and below $18 \mathrm{~km}$ on 8 October. However, above these heights, the observed echo powers are highly aspect sensitive. The height profiles of echo power in Figs. 2a and b clearly show modulation with vertical wavelength of $1-2 \mathrm{~km}$. A similar signature, however, is not present in Fig. 2c and d. On 11 October, the observed echo powers are relatively stronger at lower heights and relatively weaker at higher heights as compared to other days.

\subsection{Upper troposphere and lower stratosphere $(>15 \mathrm{~km})$}

From Figs. 2a-d it can be seen that in the upper troposphere and lower stratosphere (above $15 \mathrm{~km}$ ) normally the aspect sensitivity is high. Wherever aspect sensitivity is high, gradient in $\mathrm{N}^{2}$ is high, wind shear is low and $\mathrm{R}_{i}$ is greater than 1. This indicates that the aspect sensitivity is caused by the thermal structure of the atmosphere (Luce et al., 2001; Jain et al., 2001, 2003). Exception can be seen at 15 and $17 \mathrm{~km}$ on 8 October 2002. In general, there should be high aspect sensitivity. On this particular day, although gradient in $\mathrm{N}^{2}$ is high, shears are observed to be relatively weak and $\mathrm{R}_{i}$ is observed to be greater than 4. Accordingly, it appears that the presence of some amount of shear is possibly necessary to give rise to aspect sensitivite radar backscatters.

\subsection{Lower and middle troposphere $(<15 \mathrm{~km})$}

From Figs 2a-d it can also be seen that in lower and middle troposphere at some heights aspect sensitivity is high and at some heights it is not. Wherever aspect sensitivity is high, gradient in $\mathrm{N}^{2}$ is high (except $10-12 \mathrm{~km}$ on 25 September 2002), shear is low and $\mathrm{R}_{i}>1$. In these height regions, aspect sensitivity, however, is not as high as that at the upper troposphere and lower stratosphere. Since the static stability is lower in the lower and middle troposphere, as seen from the $\mathrm{N}^{2}$ profiles, the dynamic instability dominates over the static stability and finally resulting into turbulence. On three days (21 September, 25 September and 8 October 2002) the aspect sensitivity observed in the lower and middle tropo- sphere (e.g. below $9 \mathrm{~km}$ ) is low. It can be noticed that in all these cases shears are also relatively low $\left(\mathrm{S}^{2} \leq 10^{-4}\right)$, and, in general, $\mathrm{R}_{i}>2$. Therefore, in all these cases, though $\mathrm{R}_{i}$ is high, the aspect sensitivity is relatively weak. These observations appear to be quite similar to that observed at 15 and $17 \mathrm{~km}$ on 8 October 2002, indicating the role of shears for aspect sensitivity.

\subsection{Absence of aspect sensitivity and observations of tur-} bulent layers

Figures $2 \mathrm{a}-\mathrm{d}$ show that in the troposphere and lower stratosphere at some heights where $\mathrm{N}^{2}$ is low or negative and $\mathrm{R}_{i}$ is low, the echo power for all beam zenith angles is the same, in spite of wind shears being either high or low (see, for example, at 14.25 and $13.5 \mathrm{~km}$ on 21 September, 25 September 2002 or at 11.5 and $11.25 \mathrm{~km}$ on 8 October and 11 October 2002). This indicates that the regions are well mixed and exhibit lack of aspect sensitivity.

\section{Relation between aspect sensitivity and wind shear}

From the above presentation it appears to be clear that some minimum amount of shear is responsible for the observed aspect sensitivity. In order to examine this we have plotted the aspect sensitivity as a function of wind shear in the form of scatter plots in Fig. 3a and b, corresponding to height region $<15 \mathrm{~km}$ and $>15 \mathrm{~km}$, respectively. It is clear that the highly aspect sensitive targets are associated with wind shear of magnitude less than $0.2 \mathrm{~m} \mathrm{~s}^{-} 1 \mathrm{~m}^{-1}$. Above this value the scatterers have a tendency to lead to an isotropic nature. The figures also suggest that all the aspect sensitive targets are associated with wind shear $>0.01 \mathrm{~m} \mathrm{~s}^{-1} \mathrm{~m}^{-1}$, indicating the requirement of minimum shear for causing aspect sensitivity. It may be important to mention that our measurements allow us to observe wind shear as low as $1.3 \times 10^{-5} \mathrm{~m} \mathrm{~s}^{-1} \mathrm{~m}^{-1}$, which is decided essentially by the velocity resolution $\left(0.002 \mathrm{~m} \mathrm{~s}^{-1}\right)$ and range resolution $(150 \mathrm{~m})$ capabilities of the radar. For a detailed study, however, very high resolution measurements with resolution of the order of Bragg scale size (responsible for the radar backscattering) are required. In this connection, an appropriate study that is relevant to understanding this aspect is that made by Muschinki and Wode (1998). They have discussed on the time requirement for 2.4-m thick layers to completely diffuse when the diffusion coefficient is taken to be $2.1 \times 10^{-5} \mathrm{~m}^{2} \mathrm{~s}^{-1}$. It has been shown that the required time is $9.5 \mathrm{~h}$. However, for radar backscatter, a minimum refractive index gradient is required for it to be detected. Accordingly, the time scale in which a refractive index gradient will be invisible by a radar will be much smaller. In this context the wind shear could play a crucial role in resharpening the refractive index gradient, which could lead to aspect sensitive backscatter. 

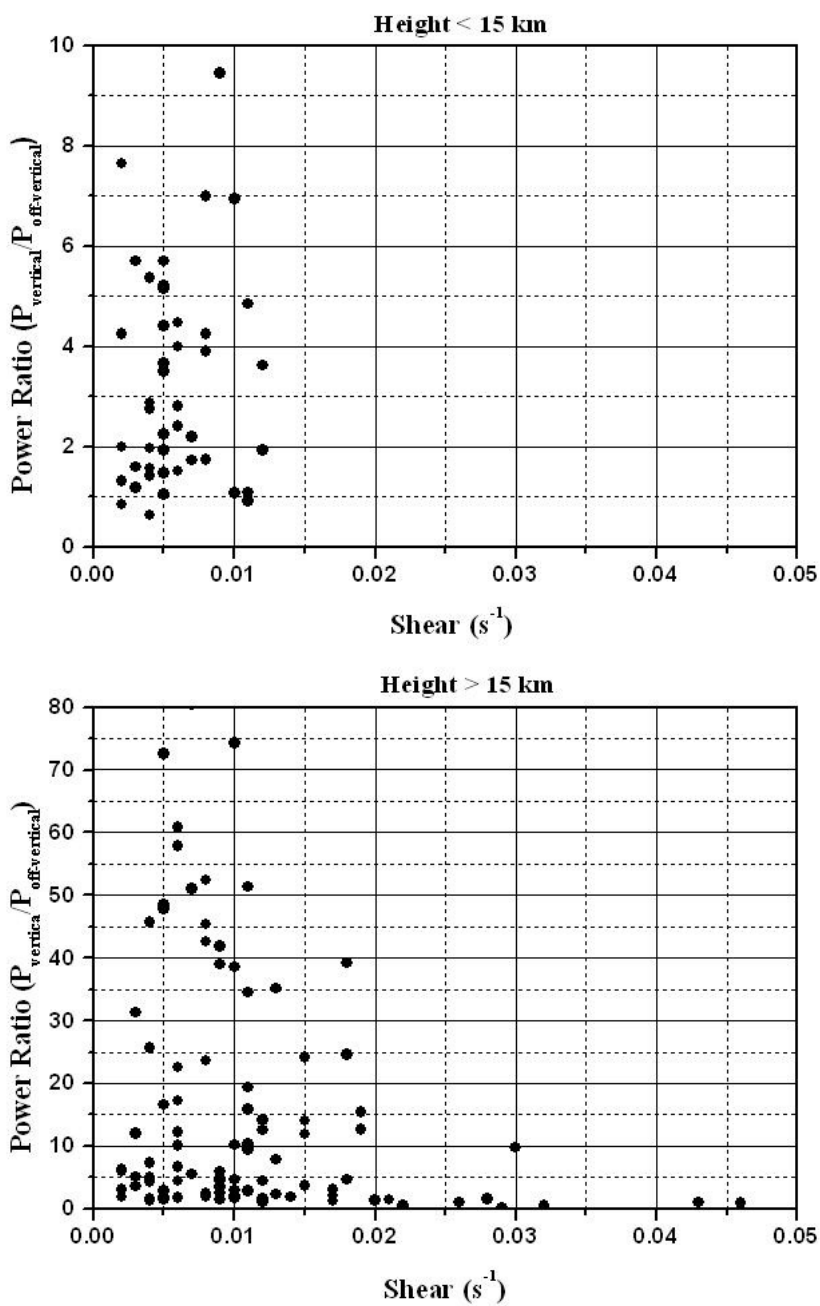

Fig. 3. Scatter plots of aspect sensitivity as a function of wind shear for height region of (a) $<15 \mathrm{~km}$ and (b) $>15 \mathrm{~km}$ where aspect sensitivity is present.

\section{Height profiles of aspect angle ( $\theta$ s) estimated for dif- ferent beam combinations}

The height profiles of $\theta \mathrm{s}$ are determined using the observed echo power for beam combinations $\left(0^{\circ}, 3^{\circ}\right),\left(0^{\circ}, 6^{\circ}\right),\left(0^{\circ}\right.$, $\left.9^{\circ}\right),\left(0^{\circ}, 12^{\circ}\right)$ and $\left(0^{\circ}, 15^{\circ}\right)$ for 21 September, 25 September, 8 October and 11 October 2002. The height profiles of $\theta$ s calculated using Eq. (2) for both the planes (i.e. E-W and NS) corresponding to each day are shown in Fig. 4a, top and bottom panels, respectively. The parameters corresponding to each of the zenith angles are obtained from the average of symmetric beam measurements. The gap region in the height profiles of $\theta \mathrm{s}$ indicates that $\theta \mathrm{s}$ could not be computed since $\mathbf{P}\left(\theta_{2}\right) \geq \mathbf{P}\left(\theta_{1}\right)$. In order to show the aspect sensitivity in two planes (E-W and N-S) scatter plots are shown in Fig. 4b for different beam zenith angles.

The following observations can be made from the height profiles of $\theta$ s presented in these figures.
1. The distinct regions of high aspect sensitivity, as seen in Figs. 2a-d, can be clearly made out from small values of $\theta$ s. In lower beam zenith angles, where $\theta$ s are less than $5^{\circ}$, the backscattered power is attributed mainly to partial reflection (Hocking and Hamza, 1997). For higher beam zenith angles, where $5^{\circ}<\theta \mathrm{s}<10^{\circ}$, the backscattered power is attributed to anisotropic turbulence. The enhanced aspect sensitivity is observed in the lower troposphere, upper troposphere and lower stratosphere on 25 September and 11 October. On other days, it is found to be in the upper troposphere and lower stratosphere.

2. Comparing the height profiles of $\theta$ s for $\mathrm{E}-\mathrm{W}$ and $\mathrm{N}-\mathrm{S}$ planes, it is seen that the parameters for the two planes differ considerably (see Fig. 4b), indicating asymmetry of aspect sensitivity in the two planes.

3. A close examination of Fig. 4a clearly shows that the radar backscattering volume in the region of high aspect sensitivity is filled with a mixture of anisotropic and isotropic backscatterers. In the low aspect sensitivity regions, the backscatterers are found to be more isotropic in nature. The anisotropic backscatterers are found to contribute more to the echo power at smaller beam zenith angles (i.e. $0^{\circ}, 3^{\circ}$ ), the isotropic backscatterers contribute more to the beam with large zenith angles $\left(6^{\circ}, 9^{\circ}, 12^{\circ}\right.$ and $\left.15^{\circ}\right)$ to the echo power. At more than $9^{\circ}$ zenith angle, the scattering is mainly due to isotropic scatterers. At angles $<9^{\circ}$, contribution from the anisotropic scattering becomes important, which is a function of beam zenith angle. In addition, when the layers are tilted or modulated by wave activities, it could result into different aspect sensitive character.

\section{Tilting of atmospheric layers and their generation mechanisms}

While computing aspect angle $(\theta \mathrm{s})$ it was noticed that at some times, at certain heights, oblique beam echo power is more as compared to vertical beam. This type of situation could arise either due to isolated intense turbulent patch advecting through the off-zenith beam or due to tilt of the echoing layers. Gage et al. (1981a, b), Gage (1986) and Hobbs and Reid (2000) suggested that this type of situation could arise due to the passage of atmospheric waves over the radar site and associated fluctuation in vertical and oblique beam echo power. If the layers are horizontally stratified in both east-west $(\mathrm{E}-\mathrm{W})$ or north-south $(\mathrm{N}-\mathrm{S})$ directions, the power is expected to be equal between the two symmetric beams. If the layers are tilted, there could be a power difference between the symmetric beams (Worthington and Thomas, 1997). To understand the causative mechanisms of such tilted layers in the present study, the MST radar measurements taken for more than $7 \mathrm{~h}$ on 25 September 2002 are selected, since such signatures are observed prominently on this particular day. 


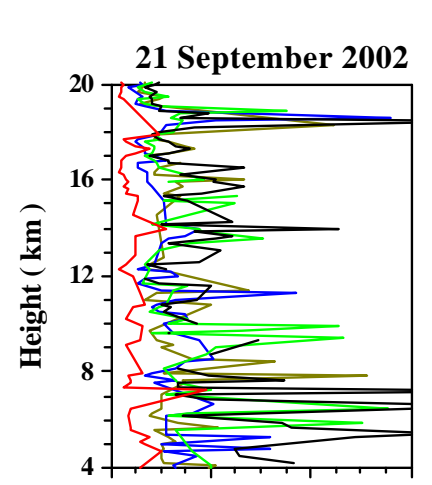

E-W Plane
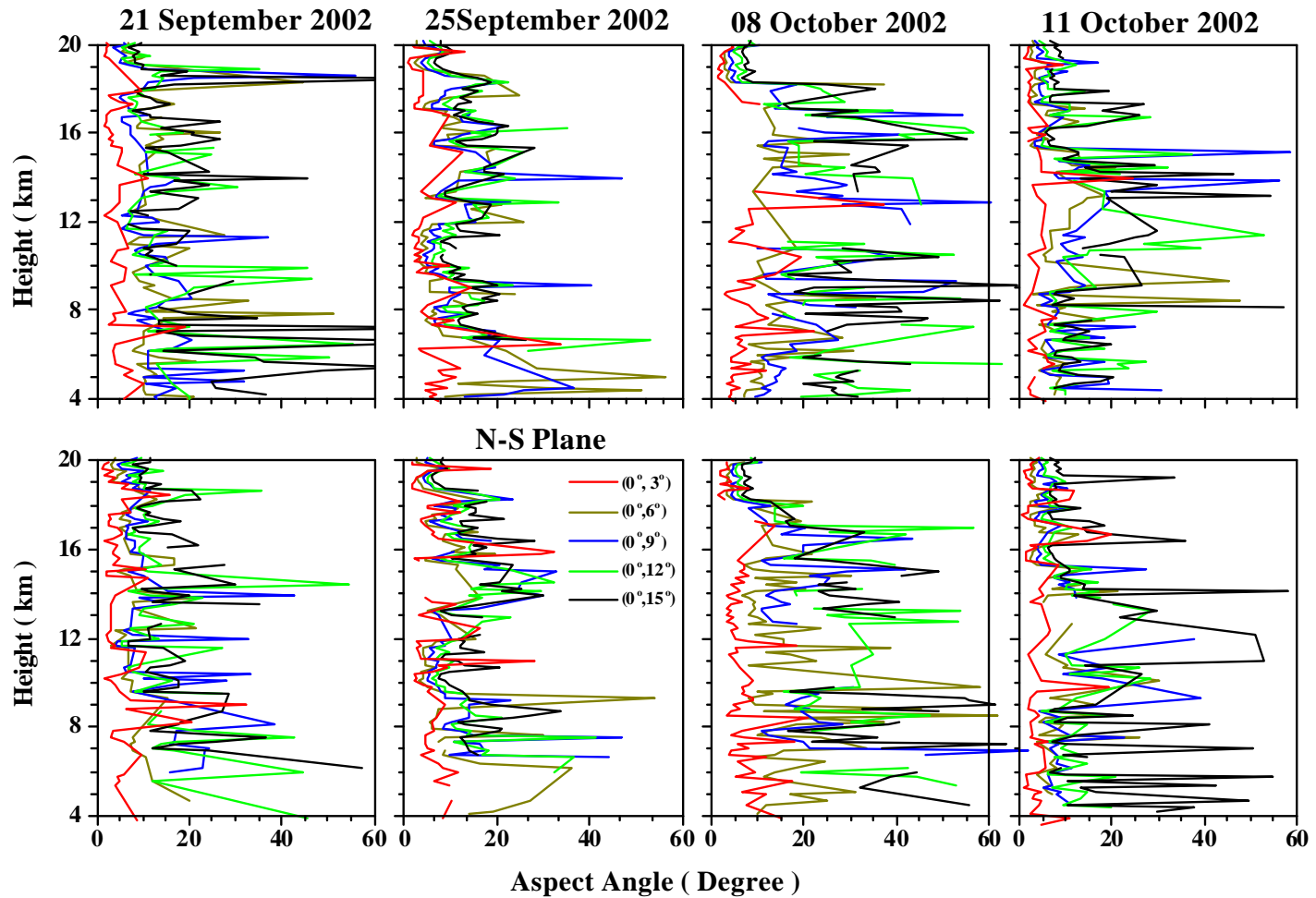

Aspect Angle ( Degree )
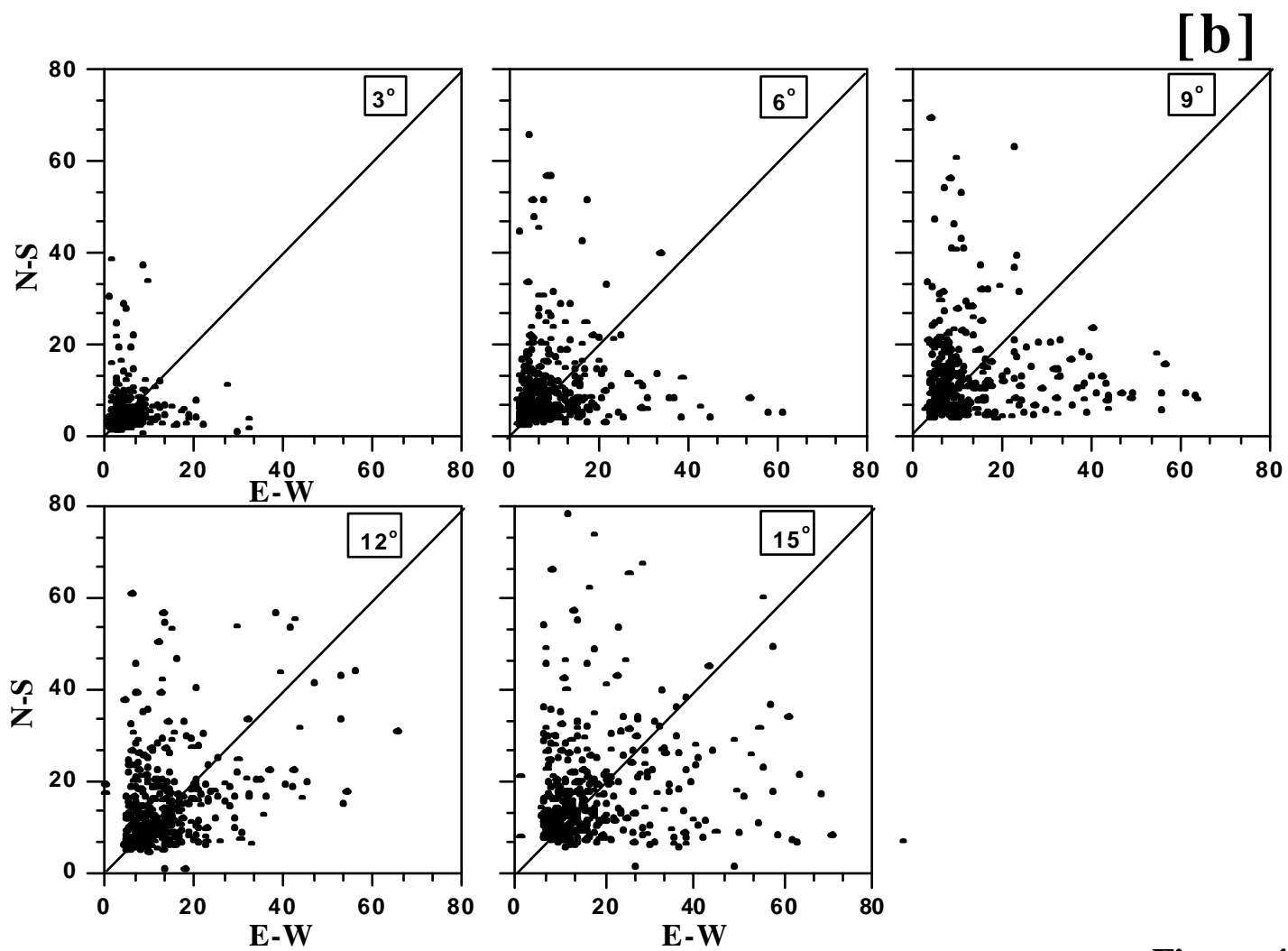

Fig. 4. (a) Height profiles of aspect angle $\left(\theta_{S}\right)$ for various beam combinations in E-W and N-S planes for 21 September, 25 September, 8 October and 11 October 2002. Each of these beam combinations use zenith beam as reference. (b) Aspect sensitivity in two planes (E-W and $\mathrm{N}-\mathrm{S}$ ) in the form of scatter plots for different beam zenith angles. 


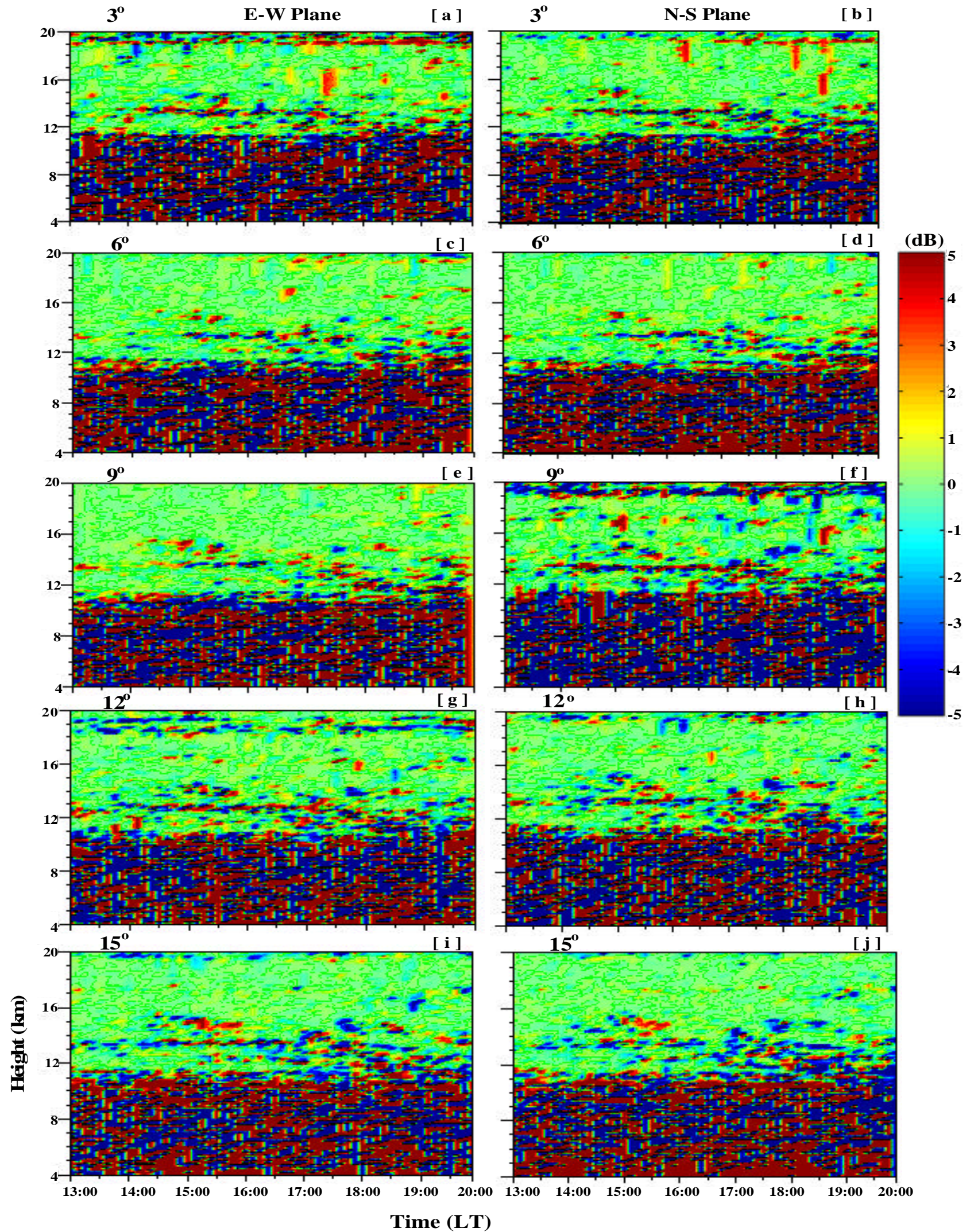

Fig. 5. Figures 5(a)-(j): Height-time intensity (HTI) maps of the difference in signal power for 25 September 2002 of the symmetric beams in both $\mathrm{E}-\mathrm{W}$ and $\mathrm{N}-\mathrm{S}$ planes at various zenith angles (e.g. $3^{\circ}, 6^{\circ}, 9^{\circ}, 12^{\circ}$ and $15^{\circ}$ ). The difference in signal powers observed in the conjugate beams is presented in logarithmic scale. 
[a]

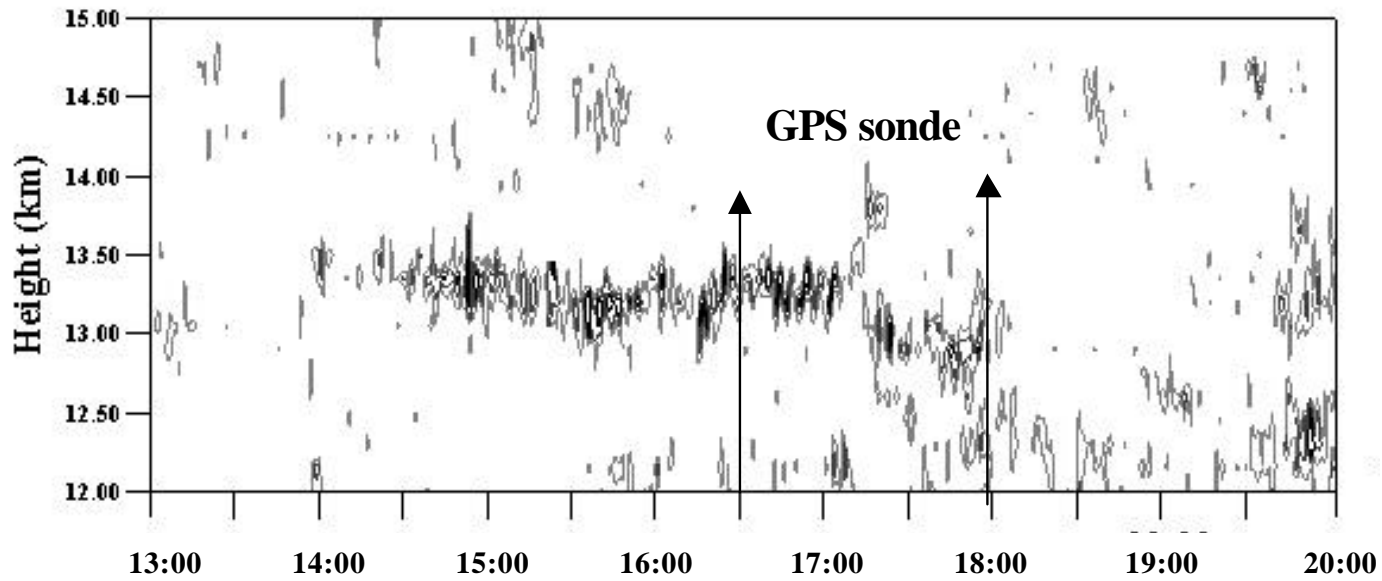

Time (LT)

[b]
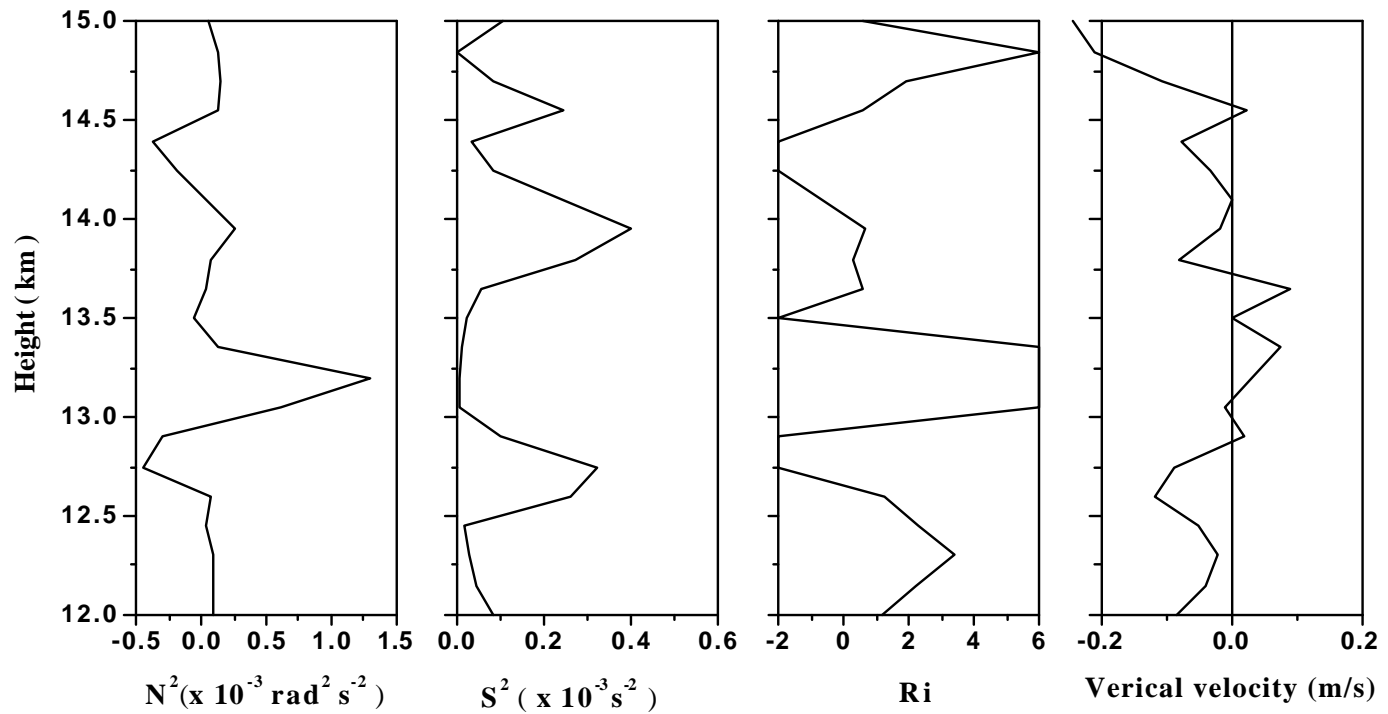

Fig. 6. Height-time-intensity plot of power burst pattern for 25 September 2002 from $12-15 \mathrm{~km}$ (upper panel). Lower panel shows the height profiles of $\mathrm{N}^{2}$, square of vertical shear, $\mathrm{R}_{i}$ and vertical velocity.

Figures 5a-j present the height-time intensity (HTI) maps of the difference in signal power in both $\mathrm{E}-\mathrm{W}$ and $\mathrm{N}-\mathrm{S}$ planes at various zenith angles (e.g. $3^{\circ}, 6^{\circ}, 9^{\circ}, 12^{\circ}$ and $\left.15^{\circ}\right)$. In these figures the difference in signal powers observed in $\mathrm{E}-\mathrm{W} / \mathrm{N}-\mathrm{S}$ are presented in logarithmic scale $(\mathrm{dB})$. From these figures it can clearly be noted that at some height levels, there is a significant difference in the received power in the two symmetric beams. This clearly indicates the tilt of the atmospheric backscatterers at these altitudes. Such power differences are observed in the altitude range of $12-14 \mathrm{~km}$ at all the beam zenith angles in both planes. But the most significant difference is seen for the beams with zenith angles of $9^{\circ}$ and $12^{\circ}$, indicating that backscatterers are tilted downwards by about 9 to $12^{\circ}$ from horizontal towards east and north. The tilt in both the planes and the enhanced power dif- ference is observed to come down as a function of time. At $19-20 \mathrm{~km}$, such power differences are also observed. These power differences indicate that at $19-20 \mathrm{~km}$, the backscatterers are tilted in towards east and north at $3^{\circ}$, towards south and some time towards north at $9^{\circ}$ beam. At $12^{\circ}$ beam it is tilted towards west and south. At lower height up to $11 \mathrm{~km}$ such power differences are also observed. But this difference is not as systematic as it is for $12-14 \mathrm{~km}$ and $19-20 \mathrm{~km}$.

One mechanism which gives rise to such a tilt is the presence of Kelvin-Helmholtz-instability (KHI) and the waves generated by the same mechanism (Worthington and Thomas, 1997). To examine the possibility of such mechanism, signal power observed in the vertical beam on 25 September 2002 is shown in Fig. 6a as a contour map. Power burst patterns can be observed at about $13.5 \mathrm{~km}$, from 
14:00-17:15 IST. After 17:15 IST, the power burst patterns are observed to be slowly disappearing and coming downward to about $12 \mathrm{~km}$. Such power burst patterns are the typical signature of KHI (Klostermeyer and Ruster, 1980; Singh et al., 1999). To confirm the same, data from GPS sonde launched at 16:30 h (marked in Fig. 6a) and the MST radar are examined. The height profiles of $\mathrm{N}^{2}$ from GPS sonde, the square of vertical shear and vertical velocity from radar and $\mathrm{R}_{i}$, using both measurements are plotted in Fig. 6b. As expected, $\mathrm{N}^{2}$ is found to be high at that height level $(13.25 \mathrm{~km})$, the shear is high at $12.85 \mathrm{~km}$ and corresponding $\mathrm{R}_{i}$ is found to be below its critical value $(0.25)$. It is also observed that the vertical velocities reverse direction at that critical height (Singh et al., 1999). This suggests that the power bursts patterns are associated with the KHI. The power bursts also come downward like power difference patterns (Fig. 5). Signatures of upward propagating atmospheric waves associated with the KHI have been seen (Das et al., 2004). At higher heights (i.e. $19-20 \mathrm{~km}$ ), the tilt can be due to the enhanced amplitudes of these waves in that height range.

\section{Conclusions}

1. The generation mechanisms of aspect sensitivity based on simultaneous MST radar and GPS-sonde observations appear to be due to high $\mathrm{N}^{2}$, low wind shear and high $\mathrm{R}_{i}$. At other heights where $\mathrm{N}^{2}$ is high, shear is relatively weak and $\mathrm{R}_{i}$ is high, there is no aspect sensitivity of the echo powers. This indicates that the aspect sensitivity is caused by the thermal structures of the atmosphere, which is clear in the upper troposphere and lower stratosphere. Further, the presence of some amount of shears seems to be necessary to give rise to aspect sensitivity of the echo power. There are some heights where observed echo intensity is high, $\mathrm{N}^{2}$ is low, shear is high and $\mathrm{R}_{i} \leq 0.25$, the echo power for all the beam zenith angles are almost the same. This shows a lack of aspect sensitivity, indicating that the regions are well mixed and hence turbulent.

2. A case study based on 25 September 2002 data shows that the tilted aspect sensitivity backscatterers are associated with KHI related waves. These waves are believed to exhibit an enhanced tilt of the aspect sensitivity backscatterers at upper heights due to their enhanced amplitude at higher heights.

Acknowledgements. The National MST Radar Facility (NMRF) is set up jointly by the Council of Scientific and Industrial Research (CSIR), Defence Research and Development Organization (DRDO), Department of Electronics, Environment, Science and Technology and Space, Govt. of India with Department of Space as a nodal agency. The NMRF is operated by the Department of Space, Govt. of India. We wish to thanks the staff of the NMRF for the collection of data used in this paper. We would like to thank G. S. Bhat, Indian Institute of Science for providing the GPS sonde receiver and supporting the data collection from Gadanki.
Topical Editor U.-P. Hoppe thanks two referees for their help in evaluating this paper.

\section{References}

Crane, R. K.: A review of radar observations of turbulence in the lower stratosphere, Radio Sci., 15, 177-193, 1980.

Damle, S. H., Chakravarthy, T., Kulkarni, A., and Balamuralidhar, P.: Aspect sensitivity measurements of backscatter with ST mode of the Indian MST radar, Indian J. Radio Space Phys., 23, 67-70, 1994.

Das, S. S., Kishore, K. K., Jain, A. R., Rao, D., N., and Nakamura, K.: Observations of trapped humidity layer and KelvinHelmholtz instability using UHF radar and GPS sonde, Radio Sci., 39, RS2024, doi: 10.1029/2003RS003003, 2004.

Doviak, R. J. and Zrinc, D.: Reflection and scatter formula for anisotropically turbulent air, Radio Sci., 19, 325-336, 1984.

Fukao, S., Harper, R. M., and Kato, S.: Radio wave scattering from the tropical mesosphere observed with the Jicamarca radar, Radio Sci., 15, 447-457, 1980.

Gage, K. S. and Green, J. L.: Evidence for specular reflection from monostatic VHF radar observations of the stratosphere, Radio Sci., 13, 991-1001, 1978.

Gage, K. S., Balsley, B. B., and Green, J. L.: Fresnel scattering model for the specular echoes observed by VHF radar, Radio Sci., 16, 1447-1453, 1981a.

Gage, K. S., Carter, D. A., and Ecklund, W. L.: The effect of gravity waves on specular echoes observed by the Poker Flat MST radar, Geophys. Res. Lett., 8, 599-602, 1981 b.

Gage, K. S.: Implications of tilting of stable layers on atmospheric measurements by clear-air Doppler radar, preprints of 23rd Conference of Radar Meteorology and Conference on Cloud Physics, 22-26 September 1986, Snowmass, Colo, Am. Meteor. Soc., Boston, Mass., 30-33, 1986.

Hobbs, B. G. and Reid, I. M.: Evidence of tilted layers in angle of arrival and Doppler beam steering power measurements, Radio Sci., 35, 983-997, 2000.

Hocking, W. K., Ruster, R., and Czechowski, P.: Absolute reflectivities and aspect sensitivities of VHF radio wave Scatterers measured with the SOUSY radar, J. Atmos. Terr. Phys., 48, 131-144, 1986.

Hocking, W. K.: Target parameter estimation, in MAP Handbook edited by Fukao, S., 30, Univ. of Ill., Urbana, 228-268, 1989.

Hocking, W. K., Fukao, S., Tsuda, T., Yamamoto, M., Sato, T., and Kato,S.: Aspect sensitivity of stratospheric VHF radar wave scatterers, particularly above 15-km altitude. Radio Sci., 25, 613627, 1990.

Hocking, W. K. and Hamza, A. M.: A quantitative measure of the degree of anisotropy of turbulence in terms of atmospheric parameters, with particular relevance to radar studies, J. Atmos. Solar Terr. Phys., 59, 1011-1020, 1997.

Hooper, D. and Thomas, L.: Aspect sensitivity of VHF scatterers in troposphere and stratosphere from comparison of powers in off-vertical beams, J. Atmos. Terr. Phys., 57, 655-663, 1995.

Hooper, D. A. and Thomas, L.: Complementary criteria for identifying regions of intense atmospheric turbulence using lower VHF radar, J. Atmos. Solar-Terr. Phys., 60, 49-61, 1998.

Jain, A. R., Jaya Rao, Y., and Rao, P. B.: Aspect sensitivity of the received radar backscatter at VHF: Preliminary observations using Indian MST radar, Radio Sci., 32, 1249-1260, 1997. 
Jain. A. R., Jaya Rao, Y., and Mydhili, N. S.: Height-time-structure of VHF back-scatter from stable and turbulently mixed atmosphere layers at tropical latitudes, J. Atmos. Solar-Terr. Phys., 63, 1455-1463, 2001.

Jain, A. R., Ghosh, A. K., Siva Kumar, V., and Kishore, K. K.: Simultaneous MST radar and radiosonde measurements at Gadanki $\left(13.5^{\circ} \mathrm{N}, 79.2^{\circ} \mathrm{E}\right)$ : Part 1 , Causative mechanism and Characteristics of Radar back-scatterers at VHF, Radio Sci., 38, 10, 1013/2000RS2527, doi:10.1029/2000RS002527, 2003.

Kawano, N., Luce, H., Yamamoto, M., and Fukao, S.: Tilted atmospheric layer and gravity wave studies by simultaneous DBS/SDI observations with the MU radar during the passage of a trough, Radio Sci., 36, 67-77, 2001.

Klostermeyer, J. and Ruster, R.: Radar observation and model computation of jet stream-generated Kelvin-Helmoltz instability, J. Geophy. Res., 85, 2829-2839, 1980.

Luce, H., Crochet, M., and Dalaudier, F.: Temperature sheets and aspect sensitive radar echoes, Ann. Geophys., 19, 899-920, 2001.

Muschinski, A. and Wode, F.: First in-situ evidence for coexisting submeter temperature and humidity sheets in the lower free troposphere, J. Atmos. Sci, 55, 2893-2906, 1998.

Narayana Rao D., Kishore, P., Narayana Rao, T., Vijaya Bhaskar Rao, S., Krishna Reddy, K., Yarraiah, M., and Hareesh, M.: Studies on refractivity structure constant, eddy dissipation rate, and momentum flux at a tropical latitude., Radio Science, 32, 1375, 1997.

Palmer, R. D., Larsen, M. F., Fukao, S., and Yamamoto, M.: On the relationship between aspect sensitivity and spatial interferometric in-beam incidence angles, J. Atmos. Solar-Terr. Phys., 60, 37-48, 1998.

Rao, P. B., Jain, A. R., Kishore, P., Balamuralidhar, P., Damle, S. H., and Viswanathan, G.: Indian MST radar 1, System description and sample vector wind measurements using ST mode, Radio Science, 30, 1125-1138, 1995.
Röttger, J. and Liu, C. H.: Partial reflection and scattering of VHF radar signals from clear atmosphere, Geophys. Res. Lett., 5, 357 360, 1978.

Röttger, J., Czechowsky, P., and Schmidt, G.: First low power VHF radar observations of tropospheric, stratospheric and mesospheric winds and turbulence at the Arecibo observatory, J. Atmos. Terr. Phys., 43, 789-800, 1981.

Singh, S., Mahajan, K. K., and Choudhary, R. K.: Detection of Kelvin-Helmholtz instability with the Indian mesospherestratosphere-troposphere radar: A case study, J. Geophys. Res., 104, 3937-3945, 1999.

Tsuda, T., Sato, T., Hirose, K., Fukao, S., and Kato, S.: MU radar observations of aspect sensitivity of back scattered VHF echo power in the troposphere and lower stratosphere, Radio Sci., 21, 971-980, 1986.

Tsuda, T., VanZandt, T. E., and Saito, H.: Zenith-angle dependence of VHF specular reflection echoes in the lower atmosphere, J. Atmos. Solar-Terr. Phys., 59, 761-775, 1997a.

Tsuda, T., Gordon, W. E., and Saito, H.: Azimuth angle variations of specular reflection echoes in the lower atmosphere observed with the MU radar, J. Atmos. Solar-Terr. Phys., 59, 777-784, $1997 b$.

Woodman, R. F. and Chu, Y. H.: Aspect sensitivity measurements of VHF backscatter made with Chung-Li radar: Plausible mechanisms, Radio Sci., 4, 113-125, 1989.

Worthington, R. M. and Thomas, L.: Long-period gravity-waves and associated VHF radar echoes, Ann. Geophys., 15, 813-822, 1997.

Worthington, R. M., Palmer, R. D., and Fukao, S.: An investigation of tilted aspect-sensitive scatterers in the lower atmosphere using the MU and Aberystwyth VHF radars, Radio Sci., 34, 413-426, 1999.

Yoe, J. G., Czechowsky, P., Ruster, R., and Schimdt, G.: Spatial variability of aspect sensitivity of VHF radar echoes in the troposphere and lower stratosphere during jet stream passages, Ann. Geophys., 12, 733-745, 1994. 